\title{
Decomposition of electricity consumption of Shandong province based on LMDI method
}

\author{
Fuqiang $\mathrm{Li}^{1}$, Huiru Zhao ${ }^{2}$, Xiaoyu $\mathrm{Han}^{2}$, Nana $\mathrm{Li}^{2}$, Yuou $\mathrm{Hu}^{3}$ \\ ${ }^{1}$ North China Grid Company Limited, Beijing, China \\ ${ }^{2}$ North China Electric Power University, Beijing, China \\ ${ }^{3}$ North China Grid Company Limited, Beijing, China
}

KEYWORDS: LMDI; electricity consumption; activity effect; structure effect; intensity effect

\begin{abstract}
In this paper, we decompose the electricity consumption changes of the whole industries of Shandong province in 2006 -2012 into activity effect, structure effect and intensity effect, using LMDI method. The results show that the expansion of economic volume mainly attributes the electricity consumption growth in this period, while industry structure adjustment and power efficiency improvement slow down the increase of electricity consumption, promoting the reduction of electricity consumption. Compared with other industries, industrial economic growth is the main driving force of electricity consumption growth, but industrial structure adjustment and efficiency enhancement are the dominant factors to reduce the electricity consumption.
\end{abstract}

\section{INTRODUCTION}

In recent years, air pollution and severe haze are concerned increasingly by more and more people, and gradually become social hotspot. The enormous pressure on energy conservation and emission reduction drives governments to speed up the adjustment of the energy consumption structure. In the structure of terminal energy consumption in Shandong province, coal has been accounting for a significant proportion. Due to the disadvantages of coal, the electricity and other secondary energy will gradually replace coal as the major component of energy consumption. Therefore, studying the factors affecting the changes of the total power consumption can accelerate transformation of the energy consumption structure.

There are multiple factors affecting the consumption of electricity. It is necessary to analyse the impact of different factors based on decomposition. Currently, decomposition techniques include structure decomposition analysis (SDA) and index decomposition analysis (IDA). Meanwhile, the IDA is divided into Laspeyre Index Decomposition and Divisia Index Decomposition. In recent years, the combination of SDA and input-output analysis method has been widely applied into the research of labor, price, energy and environment issues. However, this method will produce interaction problem in the decomposition process, which makes deviations between decomposition results and practice. Laspeyre Index Decomposition is widely used in the late 1970s and early 1980s, but there are difficulties to isolate the multiplier decomposition relationship for this method. Divisia Decomposition method is put forward by Divisia, which cannot explain the problems of "Remainder" and "0" value. The LMDI (Logarithmic Mean Divisia Index) method proposed by Ang B.W. (2004) effectively solves the unexplained "Remainder" and "0" value problem and is popular with domestic and foreign scholars.

Chunbo Ma (2008) used LMDI to decompose changes in china's energy intensity in the period of 1980-2003 into technological change and structural change. Yuhui Ou (2007) decomposed growth of Chinese energy consumption in 1985-2003. Fengdan Shi (2008) used LMDI to decompose the changes of energy consumption, coal and oil consumption of Chinese industry in 1997-2002 into production effect, structure effect and intensity effect. But Hua Liao and Yiming Wei (2011) pointed out that the sector division of the input-output tables was different from the General Statistics Department (though the name is the same), so there were deviations in the decomposition results of 
industrial energy from Fengdan Shi. Ning Sun (2011) decomposed the factors of electricity consumption into economic growth, industrial structure and power intensity based on improved Kaya identity, and she used LMDI to study these factors' impact on the three major industries of China's power consumption from 2000 to 2007.

We can see that the domestic and foreign scholars studied more about the decomposition of energy consumption and energy intensity, while less about the decomposition of power consumption. Therefore, this paper will use the LMDI method to decompose the changes of power consumption of eight major industries in Shandong Province in 2006-2012, and study the impacts on power consumption from these factors.

This paper is organized as follows. In the next section, we describe the methodology about LMDI model, and some definitions are given. Section 3 carries on decomposition of electricity consumption in Shandong province based on LMDI method. Section 4 summarizes the conclusions based on the results of the decomposition, and puts forward the corresponding electricity consumption development proposals combined with Shandong Province’s energy conservation policy.

\section{METHODOLOGY}

Total electricity consumption of the whole industries consists of electricity consumption of the eight major industries, so the total power consumption can be expressed as:

$$
E=\sum_{i} E_{\mathrm{i}}=\sum_{i} Q \frac{Q_{i}}{Q} \frac{E_{i}}{Q_{i}}=\sum_{i} Q S_{i} I_{i}
$$

where $\mathrm{E}$ is the total electricity consumption in the industry, $\mathrm{E}_{\mathrm{i}}$ is the electricity consumption of sector $i, \mathrm{Q}$ is the total industrial activity level, $\mathrm{Q}_{\mathrm{i}}$ is the activity level of sector $i, \mathrm{~S}_{\mathrm{i}}\left(=\mathrm{Q}_{\mathrm{i}} / \mathrm{Q}\right)$ and $\mathrm{I}_{\mathrm{i}}$ $\left(=E_{i} / Q_{i}\right)$ are the activity share and electricity intensity of sector $i$, respectively, Therefore, the influence factors of electricity consumption can be decomposed into three factors: economic growth, industry structure and power intensity.

According to Eq (1), the changes of electricity consumption from period t to period 0 can be decomposed into these three factors (as below Eqs (2) and (6) shown)

$$
\begin{aligned}
& \Delta E_{\mathrm{tot}}=E^{T}-E^{0}=\Delta E_{a c t}+\Delta E_{\mathrm{str}}+\Delta E_{\mathrm{int}} \\
& \Delta E_{\text {act }}=\sum_{i} \frac{E_{i}^{T}-E_{i}^{0}}{\ln E_{i}^{T}-\ln E_{i}^{0}} \ln \left(\frac{Q^{T}}{Q^{0}}\right) \\
& \Delta E_{\mathrm{str}}=\sum_{i} \frac{E_{i}^{T}-E_{i}^{0}}{\ln E_{i}^{T}-\ln E_{i}^{0}} \ln \left(\frac{S_{i}^{T}}{S_{i}^{0}}\right) \\
& \Delta E_{\mathrm{int}}=\sum_{i} \frac{E_{i}^{T}-E_{i}^{0}}{\ln E_{i}^{T}-\ln E_{i}^{0}} \ln \left(\frac{I_{i}^{T}}{I_{i}^{0}}\right) \\
& D_{\mathrm{tot}}=E^{T} / E^{0}=D_{a c t} D_{\text {str }} D_{\mathrm{int}} \\
& D_{\text {act }}=\exp \left(\sum_{i} \frac{\left(E_{i}^{T}-E_{i}^{0}\right) /\left(\ln E_{i}^{T}-\ln E_{i}^{0}\right)}{\left(E^{T}-E^{0}\right) /\left(\ln E^{T}-\ln E^{0}\right)} \ln \left(\frac{Q^{T}}{Q^{0}}\right)\right) \\
& D_{\text {str }}=\exp \left(\sum_{i} \frac{\left(E_{i}^{T}-E_{i}^{0}\right) /\left(\ln E_{i}^{T}-\ln E_{i}^{0}\right)}{\left(E^{T}-E^{0}\right) /\left(\ln E^{T}-\ln E^{0}\right)} \ln \left(\frac{S_{i}^{T}}{S_{i}^{0}}\right)\right)
\end{aligned}
$$




$$
D_{\mathrm{int}}=\exp \left(\sum_{i} \frac{\left(E_{i}^{T}-E_{i}^{0}\right) /\left(\ln E_{i}^{T}-\ln E_{i}^{0}\right)}{\left(E^{T}-E^{0}\right) /\left(\ln E^{T}-\ln E^{0}\right)} \ln \left(\frac{I_{i}^{T}}{I_{i}^{0}}\right)\right)
$$

Above $\mathrm{Eq}(2)$ is additive decomposition formula, $\mathrm{Eq}(6)$ is multiplicative decomposition formula. The subscripts act, str and int respectively indicate the effects economic growth, industry structure and power intensity.

\section{COMPUTATIONAL EXAMPLE AND ANALYSIS}

\subsection{Data and variable}

The data sources are the "Statistical Yearbook of Shandong Province", "China Economic Yearbook" and "China power statistical yearbook". Considering the limitation of data availability and research integrity, the research period is from 2006 to 2012. The total power consumption of the eight industries does not include living electricity consumption.

\subsection{The decomposition of electricity consumption}

In this paper, 2006 is set as the base period, we decompose the power consumption of the eight industries in Shandong province based on LMDI model and the changes of power consumption are decomposed into scale effect, structure effect and intensity effect. The decomposition results are shown in Table 1.

Table 1. The decomposition results of electricity consumption of the whole industries in Shandong province in 2006-2012

\begin{tabular}{|lllll|}
\hline \multicolumn{1}{l}{} & & & \multicolumn{1}{c|}{ Unity: One billion KWH } \\
\hline years & total effect & scale effect & structure effect & intensity effect \\
\hline 2007 & 30.06 & 27.22 & -2.38 & 5.21 \\
\hline 2008 & 39.98 & 53.09 & -2.93 & -10.18 \\
\hline 2010 & 58.54 & 81.72 & -8.66 & -14.52 \\
\hline 2011 & 89.77 & 115.16 & -16.04 & -9.35 \\
\hline 2012 & 121.43 & 148.31 & -22.14 & -4.74 \\
\hline
\end{tabular}

As shown in Figure 1, the scale effect changes are consistent with total effect changes. Moreover, the scale effect is far more than the structure effect and the intensity effect, which indicates that economic growth is the main driving force which promotes the increasing of power consumption for eight industries in Shandong province. The average annual growth rate of the real added value of the whole industries in Shandong province is $11.74 \%$ during 2006-2012. Due to the expansion of economic scale in 2012, the electricity consumption of the whole industries increases by 176.13 billion KWH compared to 2006, which accounts for $130.61 \%$ of the changes of power consumption in the whole industries. The structure effect has been negative in 2007-2012, which reveals that the adjustment of the industry structure in Shandong province helps to reduce power consumption and the promoting effect increase year by year. The intensity effect is negative except the year 2007, which shows that the improvement of power efficiency can help to reduce the power demand of the whole industry. In a word, due to the common effect of the expansion of economic scale, the adjustment of the industry structure and the improvement of the industry efficiency, the power consumption of the whole industries in Shandong province perform an upgrade trend, and rose to 338.13 billion KWH of 2012 from 203.28 billion KWH of 2006, increasing by 66\%. Among them, economic growth, industry structure adjustment and efficiency promotion respectively contribute 176.13 KWH, -28.09 KWH and -13.19 KWH. 


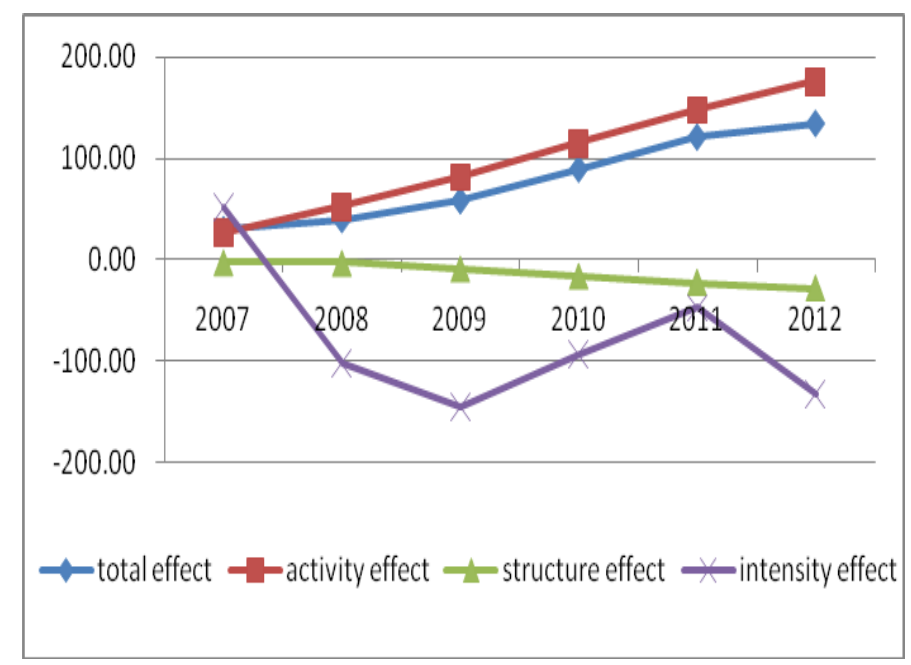

Figure 1: The decomposition results of electricity consumption of the whole industries in Shandong province in 2007-2012

\subsection{Activity effect}

As shown in Figure 2, the economic activity effects of eight major industries are positive, which suggests that the expansion of the economic scale of eight industries play a positive role in promoting the growth of electricity consumption of the whole industries. As a heavy industrial cluster, Shandong province has a lot of well-known enterprises, such as Haier and Hisense. As a result, the mode of economic growth in Shandong province obviously belongs to industry driven type. In eight industries, the activity effect of industry is far more than other industries and increases year by year. The increase of industrial added value in 2012 makes the power consumption increase by 153.76 billion KWH compared to 2006, accounting for $114.02 \%$ of the changes of the total power consumption.

Secondly, the activity effect of Public Utilities and Management Organization Industry and Business Accommodation Catering Industry respectively rank second and third in 2012, respectively. The impact on the added value of Agriculture ranks in second place in 2007-2010. However, due to the adjustment of industry structure in recent years, the development of Agriculture slows down, which makes the impact of this industry on the increasing of power consumption weakened. The activity effects of other four industries don't exceed 3.5 billion KWH, far less than that of Industry.

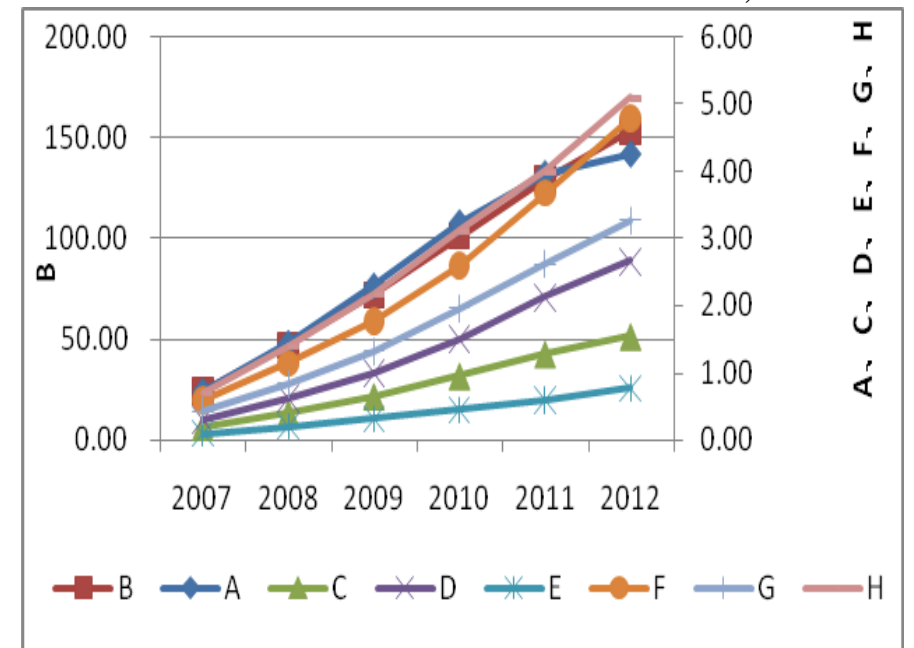

Figure 2: the activity effect of the decomposition results

Notes: $A, B, C, D, E, F, G, H$ respectively represent Agriculture, Industry, Construction Industry, Transportation, Storage and Postal Industry, Information Transmission, Computer Service and Software Industry, Business, Accommodation and Catering Industry, Finance, Real Estate, Commerce and Residential Services Industry, Public Business and Management Organization Industry in the figure2-4. 


\subsection{Structure effect}

As shown in Figure 3, the structure effect of Industry has been negative during 2007-2012, and it has a decrease trend year by year, which suggests that the adjustment of Industrial industry structure is the main driving force to promote the decline of power consumption of the whole industry. The Industry added value occupies about $50 \%$ of the whole industries, which is the leading force of economic growth in Shandong province. Therefore, the judgment of industry structure plays important role to the reduction of the power consumption in the whole industries. Due to the structure adjustment of Industry, the whole industries' electricity consumption decreases by 3.19 billion KWH in 2012 compared to 2006, accounting for $23.86 \%$ of the changes of power consumption of Shandong province.

Except Industry, the structure adjustment of Agriculture, Transportation Storage and Postal Industry, Information Transmission, Computer Service and Software Industry plays an increasingly important role in promoting the decline of power consumption of the whole industries. While the structure adjustment of Commercial Accommodation and Catering Industry, Public Utilities and Management Industry, Finance, Real Estate, Commerce and Residential Service Industry and Construction Industry promote the increase of electricity consumption.

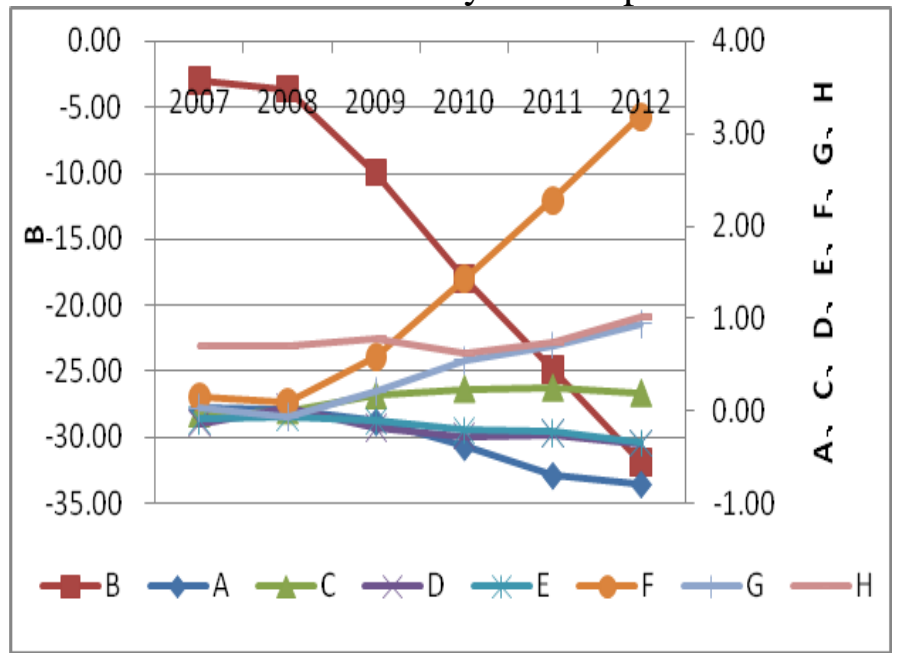

\subsection{Intensity effect}

Figure 3: the structure effect of the decomposition results

As can be seen from Figure 4, the intensity effect of Industry turns negative from positive, which indicates that the efficiency of industrial power consumption is an another driving force to reduce the power consumption in Shandong province. Since the outbreak of the global financial crisis, electricity consumption and economic development in Shandong province in 2008-2009 met a hard hit. In addition, industrial intensity fell sharply, which leads to industrial intensity effect drop to -12.79 billion KWH. After the financial crisis, Shandong province gradually restores the development of economy, and industrial intensity effect begins to improve. With the continuing impact of European debt crisis and the thorough implementation of energy conservation policy, industrial intensity effect starts to fall again in 2012, which totally makes electricity consumption of the whole industries in 2012 are less 12.50 billion KWH than that in 2006, occupying $-9.27 \%$ of the total changes of electricity consumption.

The intensity effects of Agriculture Industry, Business Accommodation and Catering Industry and Public Utilities and Management Organization Industry these three industries are almost all negative in 2007-2012, which indicates that efficiency changes of electricity consumption of these three industries have a positive promoting effect on the reduction of power consumption of the whole industries. The intensity effects of Transportation, Storage and Postal Industry, Information Transmission, Computer Service and Software Industry, Construction Industry, Finance, Real Estate, Commerce and Residential Service Industry these four industries are all positive in 2011-2012, which demonstrates that efficiency changes of electricity consumption of these four industries pro- 
mote the growth of power consumption of the whole industries. Notably, intensity effect of Transport, Storage and Postal Industry in 2007-2012 is always positive, which shows that" power substitution" and electric cars promotion impel this industry consume less energy but more electricity.

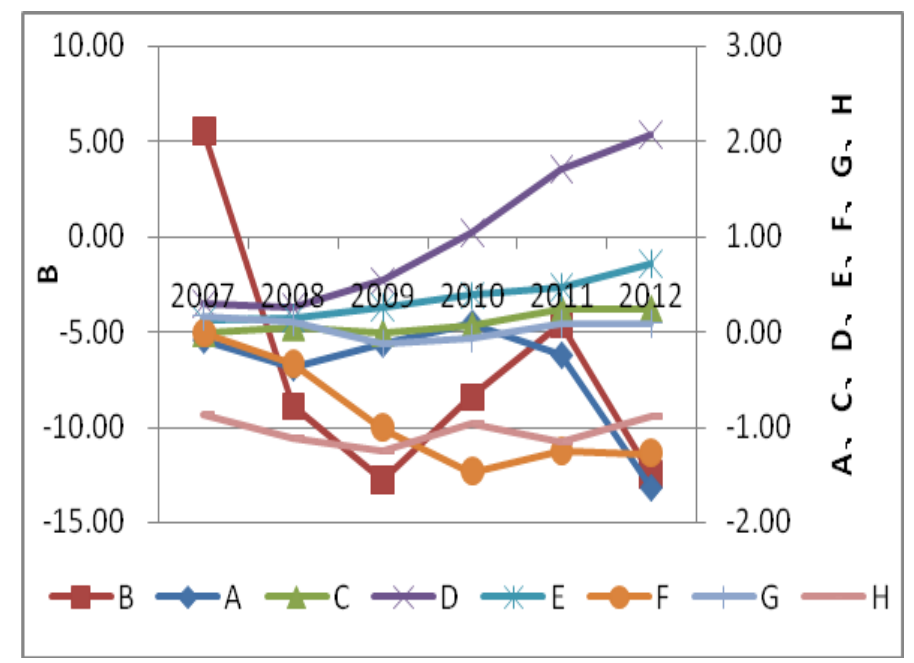

Figure 4: the intensity effect of the decomposition results

\section{CONCLUSIONS AND SUGGESTIONS}

Above we use the LMDI method to decompose the electricity consumption of the whole industries in Shandong province, and analyze the eight major industries' impacts on the changes of the total electricity consumption from economic growth, industry structure adjustment and efficiency promotion.

Through research and analysis, we find that the economic expansion of Shandong province is the main driver of increasing the total power consumption, and the industry structure adjustment and efficiency improvement reduce the electricity consumption of the whole industries, while structure effect and intensity effect are not too obvious. In order to promote the smooth progress of energy conservation and emission reduction and drive the development of low carbon green economy in Shandong province, this paper puts forward the following suggestions according to decomposition results:

(1) Transform economic growth mode and promote renewable energy power generation.

(2) Promote the optimization of industry structure adjustment, reduce the proportion in economy of high energy-consuming sectors and speed up the development of the tertiary industry.

(3) Introduce advanced electricity technology and management level, drive the use and upgrade of energy-saving technology.

\section{REFERENCES}

[1]. Ang, B.W., Choi, K.H. 1997.Decomposition of aggregate energy and gas emission intensities for industry: a refined Divisia index method. Energy J. 18 (3): 59-73.

[2]. Ang B.W., Liu, F.L., Chew, E.P. 2003. Perfect decomposition techniques in energy and environmental analysis. Energy Policy 31: 1561-1566.

[3]. Ang B. W. 2004. Decomposition analysis for policymaking in energy: which is the preferred method? Energy Policy, 32(9): 1131-1139.

[4]. Choi, K.H., Ang, B.W.. 2003. Decomposition of aggregate energy intensity changes in two measures: difference and ratio. Energy Economics 25: 615-624. 
[5]. Chunbo Ma, DavidI.Stern. 2008. China's changing energy intensity trend: A decomposition analysis. Energy Economics , 30: 1 037-1 053.

[6]. Fengdan Shi. 2008. The analysis on cause of the changes of China's industrial energy consumption. Systems Engineering 04: 55-60.

[7]. Guoquan Xu. 2008. Research on Chinese energy efficiency. Dalian university of technology.

[8]. Hua Liao, Yiming Wei. 2011. Data issues in energy economy and policy research. Technoeconomics \& Management Research, 04.

[9]. Ning Sun, Juyan Xu. 2011.The decomposition analysis of influencing factors of Chinese three major industries power consumption. Resources and Environment in the Yangtze Basin, 08.

[10]. Yuhui Ou. 2007.The decomposition of energy consumption growth in china based on LMDI. Economic Management Journal, 07.

[11]. Zhengyu Gao, Yi Wang. 2007. Decomposition analysis of changes of Chinese production energy consumption. Statistical Research, 03.

[12]. Zhiyong Han. 2004. The research on characteristics of changes of Chinese energy intensity and economic structure. Journal of Applied Statistics and Management, 01. 